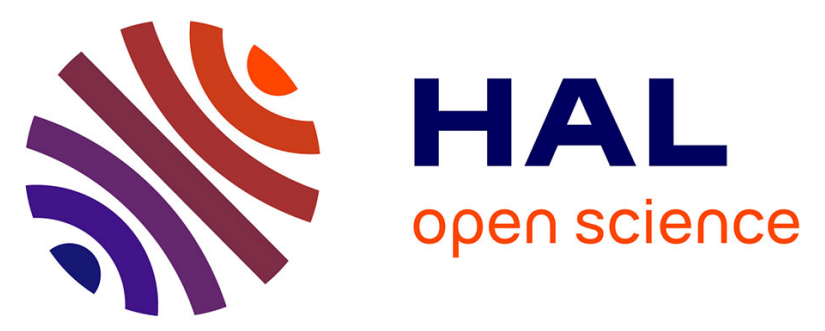

\title{
Interactive effects of land-use change and distance-to-edge on the distribution of species in plant communities at the forest-grassland interface
}

Maxime Burst, Sandrine Chauchard, Jean-Luc Dupouey, Bernard Amiaud

\section{- To cite this version:}

Maxime Burst, Sandrine Chauchard, Jean-Luc Dupouey, Bernard Amiaud. Interactive effects of land-use change and distance-to-edge on the distribution of species in plant communities at the forestgrassland interface. Journal of Vegetation Science, 2017, 28 (3), pp.515-526. 10.1111/jvs.12501 . hal-01596621

\section{HAL Id: hal-01596621 \\ https://hal.science/hal-01596621}

Submitted on 27 Sep 2017

HAL is a multi-disciplinary open access archive for the deposit and dissemination of scientific research documents, whether they are published or not. The documents may come from teaching and research institutions in France or abroad, or from public or private research centers.
L'archive ouverte pluridisciplinaire HAL, est destinée au dépôt et à la diffusion de documents scientifiques de niveau recherche, publiés ou non, émanant des établissements d'enseignement et de recherche français ou étrangers, des laboratoires publics ou privés.

\section{()(1)(2)}

Distributed under a Creative Commons Attribution - ShareAlikel 4.0 International 


\title{
Interactive effects of land-use change and distance-to- edge on the distribution of species in plant communities at the forest-grassland interface
}

\author{
Maxime Burst, Sandrine Chauchard, Jean-Luc Dupouey \& Bernard Amiaud
}

\author{
Keywords \\ Colonization credit; Edge effect; Extinction \\ debt; Forest; Grassland; Land-use change; \\ Plant community; Specialist species \\ Nomenclature \\ French national taxonomic reference TAXREF \\ v7.0 (https://inpn.mnhn.fr) \\ Received 29 April 2016 \\ Accepted 20 November 2016 \\ Co-ordinating Editor: Bryan Foster
}

Burst, M. (maxime.burst@univ-lorraine.fr), Chauchard, $\mathbf{S}$.

(sandrine.chauchard@univ-lorraine.fr), Dupouey, J.L. (jean-luc.dupouey@inra.fr), Amiaud, B. (corresponding author,

bernard.amiaud@univ-lorraine.fr )

Ecologie et Ecophysiologie Forestières, Faculté des Sciences et Technologies, Université de Lorraine, INRA, UMR 1137, F-54506, Vandoeuvre-les-Nancy Cedex, France

\begin{abstract}
Questions: What are the patterns of plant communities in terms of richness and floristic composition along stable forest-grassland interfaces? Are there specific species at the edge and/or specialist species transgressions between adjacent habitats? How does edge displacement following land-use change alter distance-to-edge plant diversity patterns? What are the relative influences of the edge effect and the edge displacement in forests and grasslands?
\end{abstract}

Location: Forests and grasslands in northeast France.

Methods: Floristic surveys were conducted in three types of forest-grassland interface, which can be stable or the result of edge displacements due to afforestation or deforestation. The sample comprised a total of 132 plots in 22 forest-grassland interfaces. Point-biserial correlation coefficients were used to classify the species into several groups in stable interfaces: forest, edge or grassland specialists and generalists. Using LMMs and Tukey's HSD tests, the total species richness and that of each species group were compared between the plot positions (i.e. distance-to-edge) and between the stable interfaces and cases of afforestation and deforestation. To evaluate the relative influence of the edge effect (plot position) and edge displacement (afforestation/deforestation) on plant community composition, CCAs and variation partitionings were performed.

Results: The largest difference in both plant community richness and composition was found between the forest and grassland edges. The highest species richness was found at the grassland edges. In addition to a high number of generalist species, a mixture of forest and grassland specialist species were predominant at the edges, and the forest specialists were almost the only transgressive species. Afforestation interfaces showed an extinction debt of grassland and edge specialist species and a colonization credit of forest specialists in recent forests. The effects of edge displacement were larger than those of the edge effect in forests, and the opposite was observed in the grasslands.

Conclusions: Forest and grassland plant communities differ strongly even over very short distances. However, the edges host a large number of forest and grassland specialist species, which explain higher species richness than in adjacent habitats. This results from interactive effects of distance-to-edge and edge displacement following land-use change.

\section{Introduction}

Plant communities result from the assemblage of species belonging to different specialist species pools and a generalist species pool. Due to contrasting environmental conditions between habitats, specialist species occupy ecological niches that are often restricted to a single habitat, while generalist species occupy broad ecological niches that overlap several habitats (Hurlbert 1978). Edge effects, which are the consequence of the environmental gradients between two habitats, may increase species distribution overlap by reducing environmental stress, thus facilitating 
the transgression of specialist species to an adjacent habitat. These environmental gradients can also generate specific conditions for the presence of edge specialist species at habitat edges (Ries \& Sisk 2004; Bergès et al. 2013).

Forest-grassland interfaces may be natural, such as some altitudinal treelines, or man-made, which is the case in most agricultural landscapes. Different patterns of plant community species richness and composition have been reported along forest-grassland interfaces depending on their origin (Lloyd et al. 2000; Strayer et al. 2003). Manmade forest-grassland interfaces can be classified as "soft" when the edges are large with gradual transitions in height and plant density, or "sharp", when the edges are narrow and characterized by abrupt changes (Herlin 2001). The "sharp" man-made forest-grassland interfaces are dependent on regular human-induced disturbances, such as mechanical cutting of trees in edges or grazing by livestock. An increase in plant species richness is more often reported near the edge than a decrease (Murcia 1995; Ries et al. 2004). For plants, this higher species richness may be explained by two complementary mechanisms: (i) spillover and (ii) edges as enhanced habitats (Ries \& Sisk 2004). Spill-over or "mass effects" refers to the dispersion of habitat specialist species into adjacent habitats. The higher species richness near edges is due to proximity and to the inability of species to penetrate more deeply into the adjacent habitat (Ries \& Sisk 2004). Edges as enhanced habitat may allow the establishment and persistence of a mixture of species from adjacent plant communities through the reduction of environmental stress (Marchand $\&$ Houle 2006) and/or allow the existence of edge specialist species that require the environmental conditions found at the edge (Lloyd et al. 2000; Ries \& Sisk 2010).

Man-made forest-grassland interfaces vary in stability over time due to land-use changes (Harper et al. 2005; Pellissier et al. 2013). When these interfaces are stable over a long period of time, the edges are considered to be less permeable to abiotic and biotic flows (Harper et al. 2005). Plant communities, at least in terms of species composition, should strongly diverge on either side of the forestgrassland boundary, favouring specialist species to the detriment of generalists. In contrast, edge displacements by afforestation or deforestation create transient habitats that are more favourable to generalist species (Vellend et al. 2007; Bergamini et al. 2009). In the case of unstable edges, recent habitats are prone to plant extinction debts and colonization credits (also called immigration credits; Jackson \& Sax 2010). Some species in the pre-existing plant communities can take a long time to disappear while others, which belong to future plant communities that are expected to become established after the land-use change, may stay absent for a long time (Bossuyt et al. 1999; Verheyen et al. 2003). The role of these historical factors in present edge patterns has seldom been addressed. Bergès et al. (2015) showed that, due to the expansion of forests in France since 1830 and to the preferential localization of the recent forests at the peripheries of ancient forests, the colonization credit can be confused with edge effects over long distances (sometimes $>1 \mathrm{~km}$ ). For species-poor preexisting plant communities, as in the case of the afforestation of former agricultural fields, the extinction debt process is weak (Vellend et al. 2007). The study of displacement of forest-grassland boundaries offers the opportunity to characterize the role of extinction debt in initially species-rich communities. For example, if colonization by new species is faster than the extinction of the original species following edge displacement, the result should be a higher number of habitat specialist species (mixture of forest and grassland specialists) in recent habitats (Jackson $\mathcal{E}$ Sax 2010).

Therefore, edge effect and edge displacement could have interactive effects on the distribution of species in plant communities at habitat interfaces, such as between forests and grasslands. The study of edge displacements between forests and grasslands allowed us to: (i) characterize the distribution of specialist and generalist species pools along forest-grassland interfaces; (ii) assess the effect of edge displacement on these species distributions in recent habitats; and (iii) disentangle the relative influence of edge displacement (extinction debt and colonization credit) from that of the edge effect (spill-over and edges as enhanced habitats) on the presence or absence of plant species in ancient and recent habitats.

Our specific research questions were as follows:

1 Along stable forest-grassland interfaces, what are the patterns of plant communities in terms of richness and floristic composition? Are there specific species at the edge and/or transgressions of specialist species (forest or grassland specialists) between adjacent habitats?

2 How does edge displacement alter the observed distance-to-edge plant diversity patterns? What are the relative influences of the edge effect and edge displacement in forests and grasslands?

\section{Methods}

\section{Study area and site selection}

The study was conducted in the Lorraine regional natural park (PNRL) in northeast France $\left(48^{\circ} 54^{\prime} \mathrm{N}, 6^{\circ} 03^{\prime} \mathrm{E} ; 215-\right.$ $277 \mathrm{~m}$ a.s.l.). The climate is semi-continental, with annual rainfall and temperature averaging $714 \mathrm{~mm}$ and $10{ }^{\circ} \mathrm{C}$ for the period of 1981-2000, respectively. The geological substrate is mainly clayey marl from the Oxford Clay formation in the western area and the Keuper formation in the eastern area. 
The availability of ancient and recent large-scale vectorized land-use maps in the Lorraine region made it possible to preselect forest-grassland interfaces in an initial study area of nearly $2000 \mathrm{~km}^{2}$. Edge displacements were characterized by comparing the land uses of French Etat-Major maps (established between 1826 and 1831) and the current land-use map (established between 1997 and 2014) using a GIS (ArcGIS ${ }^{\circledR}$, v.10.2; ESRI, France). Areas where land use had not changed since 1826-1831 were categorized as ancient, and areas where land use was different were qualified as recent. For each preselected interface, series of old aerial photographs (spaced apart up to $10 \mathrm{yr}$ maximum between 1931 and 2014; http://www.geoporta il.gouv.fr) were photo-interpreted to confirm the origin and the maintenance of forest and grassland over time.

To avoid confounding factors other than the edge effect and the edge displacement, the interfaces were then selected according to several environmental criteria: homogeneity of topographic positions (thalwegs and footslopes) among interfaces and adjacent land uses based on the calculation of a topographic position index (TPI) at a scale of $250 \mathrm{~m}$ (Land Facet Corridor Designer, v.1.2.884, http://www.jennessent.com), minimum area of both adjacent land uses $(\geq 1$ ha) to ensure having a core area, linearity of the edge to avoid multiple edge effect, no intersection by a path or stream, absence of war disturbances (e.g. trenches), and finally, mature forests without recent logging and meso-hygrophilous meadow grasslands without apparent grazing. The choice to select sites among thalwegs and footslopes was due to the nearly exclusive distribution of ancient grasslands in these topographic conditions (over $70 \%$ of the ancient grassland area in thalwegs or footslopes according to the TPI). With GIS, 113 forestgrassland interfaces were preselected, and after field surveys, the interfaces that did not exactly comply with the above criteria were discarded. Ultimately, 22 forest-grassland interfaces were retained for our study.

\section{Study design}

Three types of interfaces with different habitat histories were sampled: (i) stable interface, i.e. ancient edge with ancient forest (AF) adjacent to ancient grassland (AG) (eight sites); (ii) unstable interface linked to an afforestation process, i.e. recent edge with recent forest (RF) adjacent to ancient grassland (AG) (seven sites); and (iii) unstable interface linked to a deforestation process, i.e. recent edge with ancient forest (AF) adjacent to recent grassland (RG) (seven sites). Therefore, four habitat histories (AF, AG, RF, RG) combining two histories (ancient, recent) and two habitats (forest, grassland) were sampled. Each interface included a transect of six plots that were positioned in each habitat at three increasing distances from the forest-grassland boundary, referred to as the plot position: edge, periphery and core (Appendices $\mathrm{S} 1$ and S2). Each plot had an area of $2 \mathrm{~m} \times 50 \mathrm{~m}$ $\left(100 \mathrm{~m}^{2}\right)$ and was oriented parallel to the forest-grassland boundary. The boundary between forest and grassland was defined according to the following three criteria: (i) the line running tangentially to the trunks of trees belonging to the upper canopy layer, (ii) the outer limit of shrubs where the tree trunks were spaced more than $10 \mathrm{~m}$ apart and, failing these, (iii) the limit of grassland mowing. Forest and grassland edge plots were placed adjacent on each side of the boundary. In the case of presence of a ditch (15 out 22 sites), they were slightly moved apart in order to avoid this heterogeneity. Consequently, edge plots centres were located $3.7 \mathrm{~m}$ apart on average. To avoid multiple edge effects in grasslands and because the depth of influence of the edge effect is recognized in the literature as being lower for grasslands (Dutoit et al. 2007; Gieselman et al. 2013) than forests (Murcia 1995; Harper et al. 2005), plots were placed closer to the boundary at grassland peripheries and cores ( 5 and $25 \mathrm{~m}$, respectively) than at forest peripheries and cores ( 15 and $50 \mathrm{~m}$, respectively). The sample comprised a total of 132 plots in 22 forestgrassland interfaces.

\section{Vegetation survey}

Floristic surveys were conducted from May to June 2014 and before the first mowing for all grasslands. In each plot, all ligneous species $<1-m$ high and all herbaceous vascular species regardless of height were inventoried. The abundance-dominance of all species was noted using a BraunBlanquet-like scale, recoded for analysis from 1 to 9 (Van der Maarel 1979). Although taller ligneous species were also recorded, they were not used in the subsequent analyses because there were systematically absent from the grasslands due to mowing.

\section{Data analysis}

\section{Species pools and species richness}

To determine which species were forest, edge or grassland specialists, we grouped the plots along the forest-grassland interface into three pairs of habitats referred as forest: forest core + forest periphery, edge: forest edge + grassland edge, grassland: grassland periphery + grassland core. We then used the point-biserial correlation coefficient $\left(r_{\mathrm{pb}}\right)$, which compares the abundance of species between one habitat and the others and gives a value of negative or positive association bounded between -1 and 1 for this habitat (De Cáceres \& Legendre 2009). For each species, only the habitat with the largest positive value was considered, and the significance of the association tested using a 
permutation test with 9999 iterations. Species with $P$-value $<0.05$ were considered as specialists, in contrast to generalists or infrequent species $(P \geq 0.05)$. To avoid potential biases due to extinction debt or colonization credit following edge displacements, $r_{\mathrm{pb}}$ coefficient calculations were only performed on stable interfaces (eight sites). As a first step, we calculated the $r_{\mathrm{pb}}$ coefficient for the detection of specialist species for each single habitat (forest, edge or grassland). As a second step, we used an extension of the $r_{\mathrm{pb}}$ coefficient (De Cáceres \& Legendre 2009) to detect specialist species of single habitats or of their combinations (forest, edge, grassland, forest + edge, forest + grassland, edge + grassland). The separation of species restricted to one of the habitats and those preferentially found in two of the three habitats allowed us to more finely characterize species preferences along the interface (De Cáceres et al. 2010). Generalist species were defined as those not significantly related to any habitat or habitat combination, but having a frequency of occurrence larger than the minimum frequency observed among specialist species (Appendix S3).

Species richness was compared between plot positions in stable interfaces (48 plots). Total species richness and richness of four groups of species were compared: forest specialists, edge specialists, grassland specialists and generalist species. These four groups were based on the $r_{\mathrm{pb}}$ coefficient of association for a single habitat. The significance levels of the differences in species richness were calculated for all species and each species group between plot positions with Tukey's HSD tests following linear mixed models (LMMs) with plot position as a fixed effect and site as a random effect. For each plot position separately, the species richness was also compared between interface types (afforestation, stable and deforestation) using the same tests.

\section{Plant community composition}

To assess the relative influence of edge displacement and the edge effect on the distribution of species pools in plant communities, we conducted (i) a canonical correspondence analysis (CCA) of the species abundance for all forest and grassland plots ( 132 plots) constrained by the sampling scheme, i.e. the site identity (22 levels) and the combination of the six plot positions and the two histories ancient or recent (12 levels), and (ii) variation partitioning of community composition as a function of plot position and history, using the total set of plots or separately for forests and grasslands. To reduce the noise due to infrequent species, only species with three or more occurrences were taken into account in the CCA and variation partitionings (225 species for all plots, 166 species for forest plots and 210 species for grassland plots).
For each type of interface considered separately, the scores of the plots along the first two CCA axes were compared between plot positions with Tukey's HSD tests following linear models with plot position as a fixed effect. For each plot position considered separately, the scores along the first and second CCA axes were also compared between types of interfaces. In addition, the community weighted mean indicator values (CWMIV) for light availability $(\mathrm{L})$, temperature requirement $(\mathrm{T})$, humidity $(\mathrm{F})$, soil $\mathrm{pH}(\mathrm{R})$ and $\mathrm{N}$ availability $(\mathrm{N})$ were calculated using the plant indicator values of Ellenberg et al. (1992). For each environmental variable, CWMIV is the mean of the indicator values of all the plant species present in a plot weighted by their abundance. The CWMIVs were used for the interpretation of the CCA axes using Spearman's rank correlation test.

The three variation partitionings were each based on one CCA and two partial CCAs according to Borcard et al. (1992). The CCA was constrained by the plot position (six plot positions for the analysis of both habitats taken together or three plot positions for the separate analyses of forests and grasslands) and the history (four habitat histories, AF, AG, RF, RG, for the analysis of both habitats, or two histories, ancient and recent, for the separate analyses of each habitat). A first partial CCA was constrained by the history after removing the effect of the plot position and then a second partial CCA was inversely constrained by the plot position after removing the effect of the history. For each variation partitioning, the results are presented in a Venn diagram as the percentage of total variation explained uniquely by each explanatory variable and their joint effect.

Statistical analyses were carried out with $\mathrm{R}$ 3.0.2 (R Foundation for Statistical Computing, Vienna, AT) and the following packages were used: indicspecies for calculating $r_{\mathrm{pb}}$ coefficients, nlme for LMMs, vegan for CCAs and VennDiagram for drawing Venn diagrams after the CCAs.

\section{Results}

\section{Species pools}

In total, 301 species were found in the 132 forest and grassland plots. According to the type of interface (stable, afforestation, deforestation), 244, 224 and 218 species were found, respectively. When testing the species association with single habitats in stable interfaces, the $r_{\mathrm{pb}}$ coefficient significantly distinguished 79 specialist species, including 28 forest specialists, 12 edge specialists and 39 grassland specialists (Appendix S4). The other 165 species were either generalists ( 51 species) or were too infrequent to appear significant (114 species). When testing species associations with single and combined habitats, the $r_{\mathrm{pb}}$ coefficient significantly distinguished 83 specialist species, 
including 14 forest specialists, 21 forest and edge specialists, eight edge specialists, seven edge and grassland specialists and 33 grassland specialists (Appendix S5). Among the other 161 species, 47 were generalists and 114 infrequent. Half of the 28 forest specialist species identified by the first classification transgressed into edges, i.e. preferred the combination 'forest + edge' in the second classification, while only five of the 39 grassland specialists preferred the combination 'edge + grassland'.

\section{Species richness along stable forest-grassland interfaces}

When comparing the species richness per plot position in stable interfaces, the total species richness in grasslands was significantly higher at the edge and decreased towards the core (Fig. la). No significant differences were observed in forests $(P>0.05)$. There was an abrupt decrease in total species richness from grassland edge to forest edge, although these two plots were located a few meters apart. As expected, the number of forest specialists decreased from forest core to grassland core, regularly and significantly from the forest to grassland periphery (Fig. lb). A reverse but stronger pattern was observed for grassland specialists: the gap in species richness between the grassland edge and forest edge was larger, and these grassland species were nearly entirely lacking at all three forest positions. Species richness of edge specialists, but also of generalist species, was highest at the edges of each habitat and more or less significantly decreased towards the cores. Edge specialists were still significantly present in forests, at the periphery and core positions, but nearly absent in grasslands.

\section{Species richness at each plot position according to the type of interface}

Total species richness at the three forest positions (core, periphery and edge) was higher in the afforestation than in stable and deforestation interfaces (Fig. 2a). At the three grassland positions, in contrast, total species richness in the afforestation interfaces appeared lower (but not significantly) than in the stable interfaces, particularly at the grassland edge, while total species richness in the deforestation interfaces was highest for all three positions.

For forest specialists (Fig. 2b), species richness in the afforestation interfaces appeared lower (but not significantly) than in the stable and deforestation interfaces, regardless of position. Conversely, when examining grassland specialists (Fig. 2c), species richness in the afforestation interfaces was significantly higher than in the stable and deforestation interfaces for the three forest positions. For edge specialists (Fig. 2d), the species richness of the afforestation interfaces was significantly higher than that of the stable interfaces at the forest core. Regarding generalist species (Fig. 2e), the species richness in the afforestation interfaces was higher at the three forest positions, significantly in the forest edge, but lower in the grassland edge and periphery compared to the stable and deforestation interfaces. Therefore, generalist species richness was higher in recent forest compared to ancient forest but also (a) All species

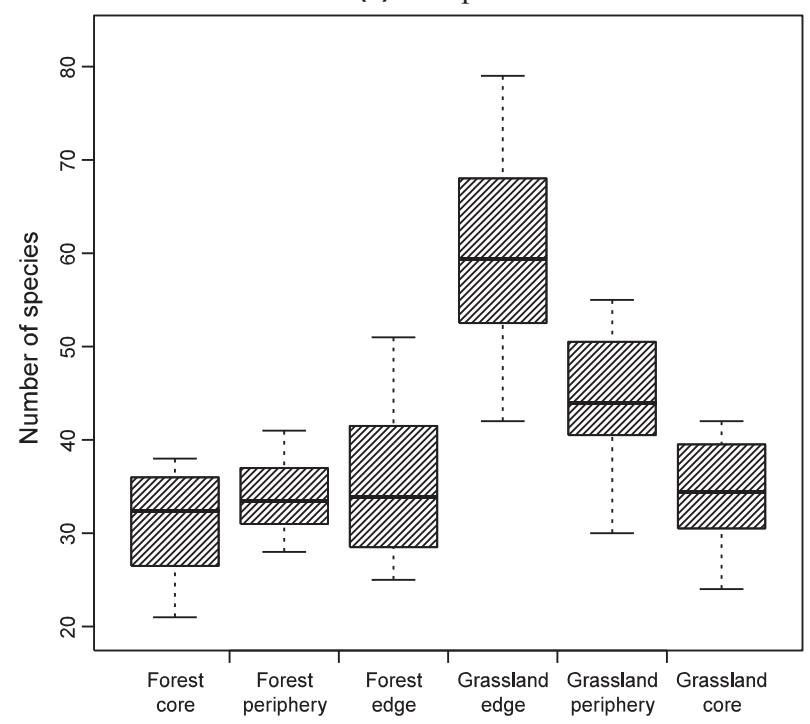

(b) Species groups

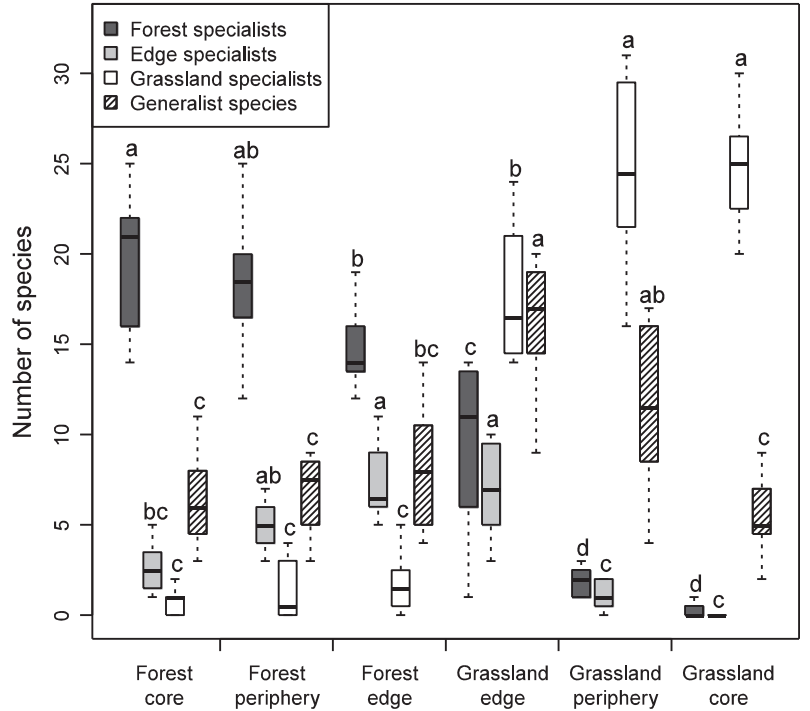

Fig. 1. Species richness according to plot position for (a) all species and (b) each group of species separately along stable forest-grassland interfaces (48 plots, 244 species). For all species and within each group of species, plot positions with different letters significantly differ in species richness $(P<0.05)$ according to a LMM and Tukey's HSD test. 
(a) All species

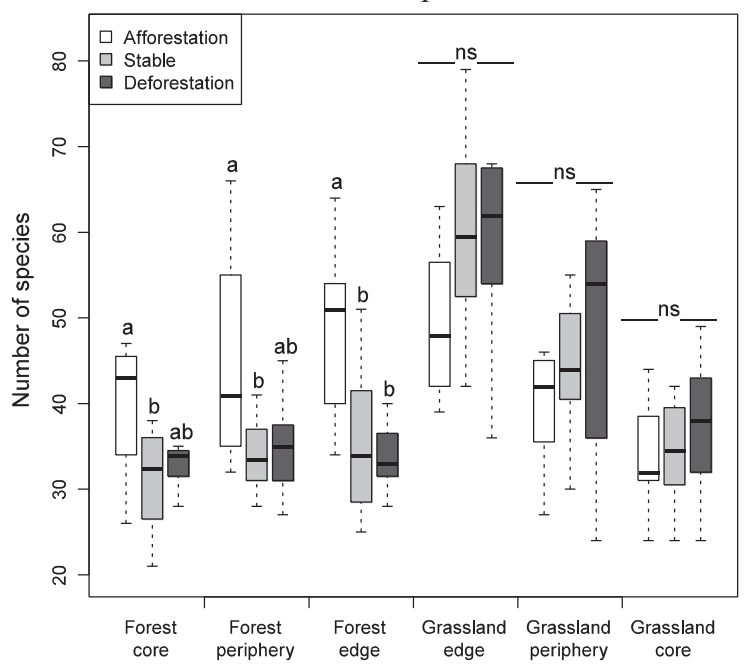

(b) Forest specialists

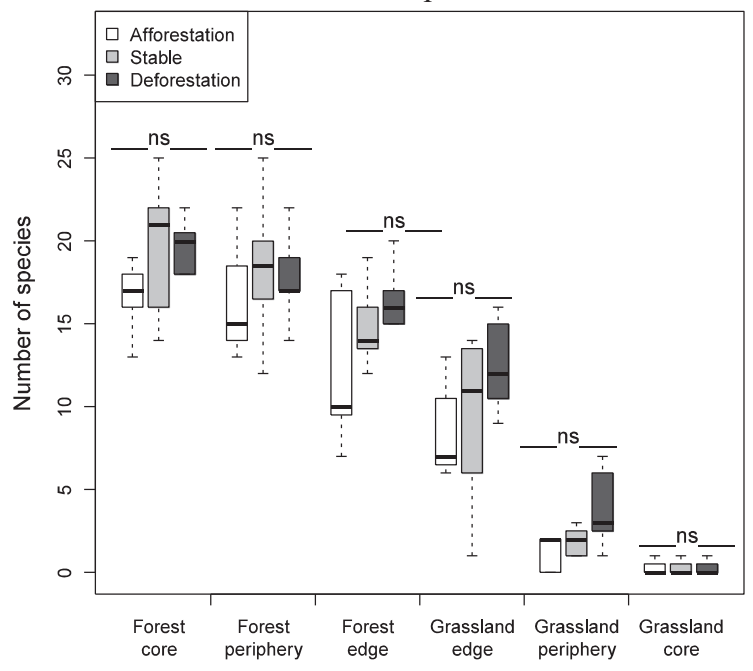

(d) Edge specialists

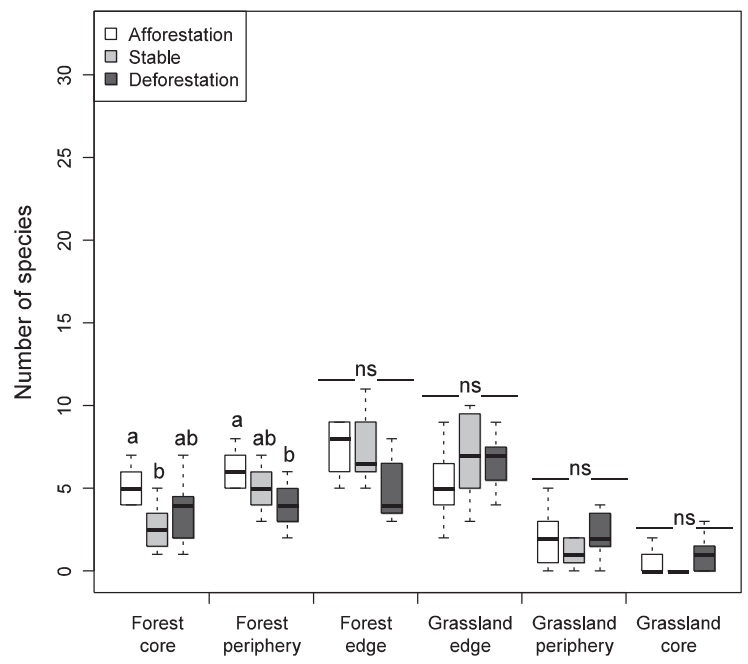

(c) Grassland specialists

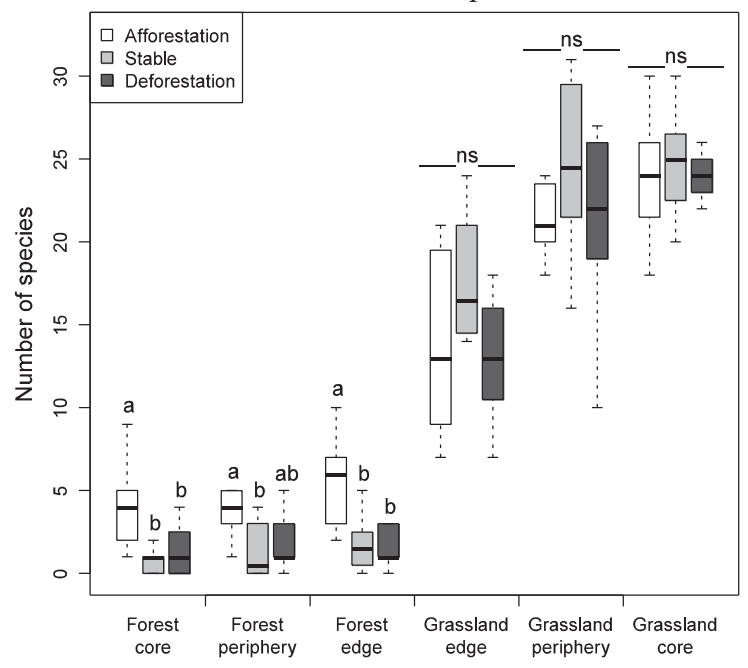

(e) Generalist species

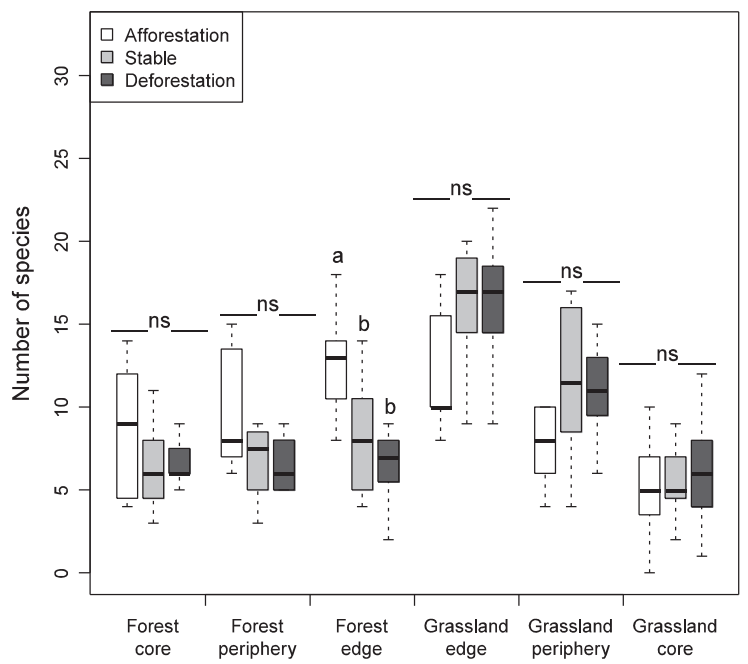


Fig. 2. Species richness of (a) all species, (b) forest specialists, (c) grassland specialists, (d) edge specialists and (e) generalist species according to plot position along each type of forest-grassland interface: afforestation (recent forest/ancient grassland) (42 plots, 224 species), stable (ancient forest/ancient grassland) (48 plots, 244 species) and deforestation (ancient forest/recent grassland) (42 plots, 218 species). Within a plot position, types of forestgrassland interface with different letters significantly differ in species richness $(P<0.05)$ according to a LMM and Tukey's HSD test (n.S.: no significant difference).

lower in the grassland edge and periphery when the adjacent forest was recent (afforestation).

Relative influences of the edge effect and edge displacement on plant community composition

In the CCA, all the constraining variables combined explained $47.8 \%$ of the total variation in species composition. The first axis (13.6\% of the total variation) was mainly related to plot position along the forest-grassland gradient (Fig. 3). It was positively correlated (higher values in grasslands) with the CWMIV of light availability and soil humidity and negatively correlated (higher values in forests) with the CWMIV of $\mathrm{N}$ availability, soil $\mathrm{pH}$ and temperature (Table 1). The second CCA axis (3.9\% of the total variation) was mainly related to the history (Fig. 3), separating the former forest habitats on the negative side (AF, RG) and the former grassland habitats on the positive side (RF, AG). It was positively correlated (higher values in former grasslands) with the CWMIV of soil humidity, N availability and light availability (Table 1).
Along the first CCA axis, the largest floristic difference between two successive plot positions was found between the forest and grassland edges of stable interfaces despite their spatial proximity (Fig. 3); this difference was lower in afforestation and deforestation interfaces. For the three types of interface, the periphery of each habitat was floristically more different from the edge than the core, again despite the closer spatial proximity. In addition, the three

Table 1. Spearman's rho correlations between the first two axes of CCA and the CWMIV for light (L), temperature (T), soil humidity (F), soil pH (R) and $\mathrm{N}$ availability $(\mathrm{N})$. Significant $P$-values are indicated by background shading.

\begin{tabular}{|c|c|c|c|c|}
\hline \multirow[t]{2}{*}{ CWMIV } & \multicolumn{2}{|c|}{ CCA Axis 1} & \multicolumn{2}{|c|}{ CCA Axis 2} \\
\hline & $\rho$ & $P$-value & $\rho$ & $P$-value \\
\hline L & 0.89 & $<0.001$ & 0.28 & 0.001 \\
\hline $\mathrm{F}$ & 0.53 & $<0.001$ & 0.45 & $<0.001$ \\
\hline $\mathrm{N}$ & -0.28 & 0.001 & 0.31 & $<0.001$ \\
\hline $\mathrm{R}$ & -0.71 & $<0.001$ & -0.07 & 0.422 \\
\hline $\mathrm{T}$ & -0.72 & $<0.001$ & 0.07 & 0.402 \\
\hline
\end{tabular}

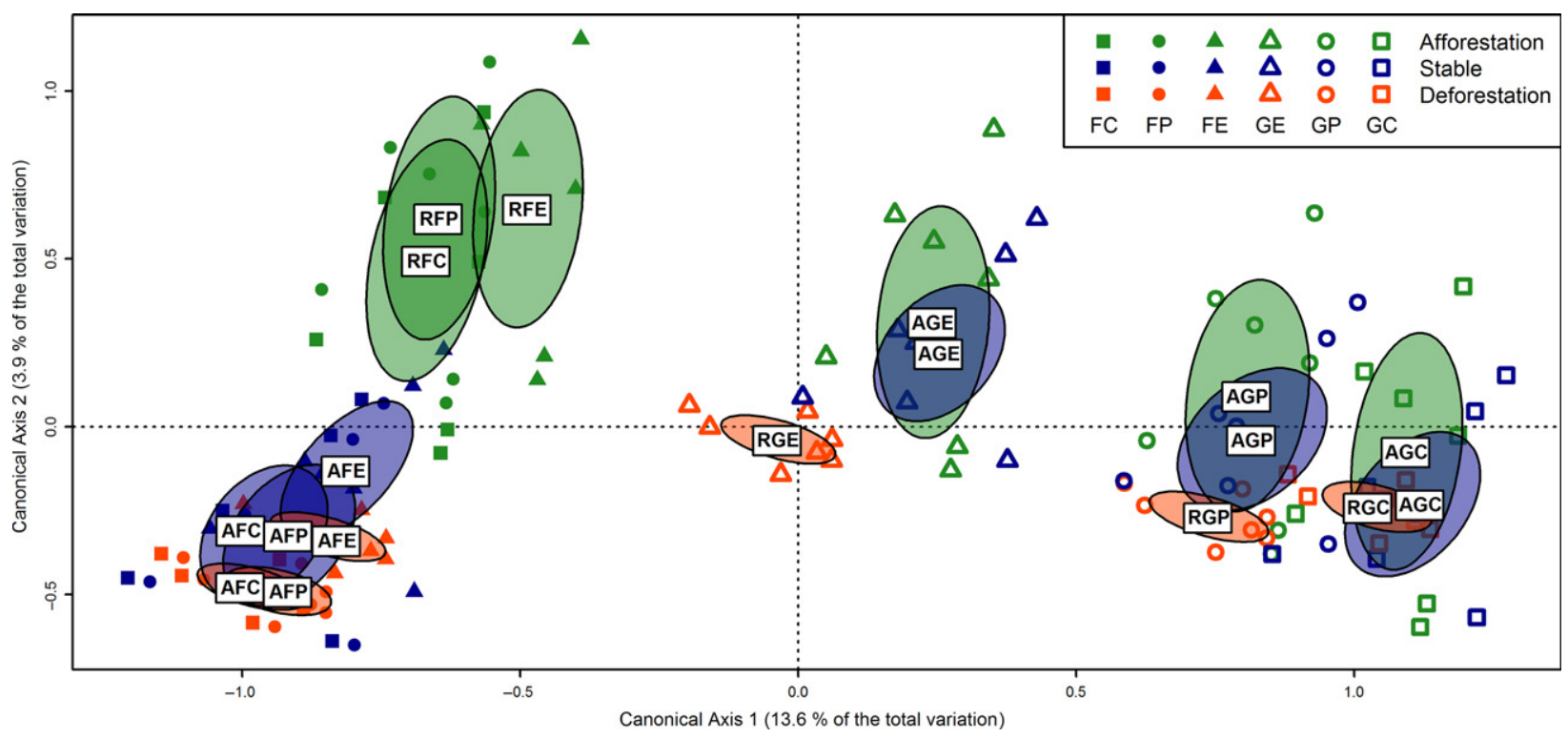

Fig. 3. Canonical correspondence analysis of species abundance in all plots (132 plots, 225 species) as constrained by the sampling scheme, i.e. site and combination of plot position and history. For each type of forest-grassland interface and each plot position, dispersion ellipses are drawn using a $\mathrm{Cl}$ of 0.95. Their labels are the combination of history and plot position. Type of interface: afforestation, stable and deforestation. History: A (ancient) and R (recent). Plot position: FC (forest core), FP (forest periphery), FE (forest edge), GE (grassland edge), GP (grassland periphery) and GC (grassland core). 
Table 2. Significance of the differences between (a) the plot positions for each type of interface, and (b) the types of interface for each plot position along the first two axes of a CCA constrained by the sampling scheme, i.e. site and combination of plot position and history. Different letters indicate significantly different average scores $(P<0.05)$ on the CCA axes, in decreasing order from ' $a$ ' to 'e', according to a linear model and Tukey's HSD test (n.s.: no significant differences). Type of interface: afforestation, stable and deforestation. Plot position: FC (forest core), FP (forest periphery), FE (forest edge), GE (grassland edge), GP (grassland periphery), GC (grassland core).

\begin{tabular}{|c|c|c|c|c|c|c|}
\hline & FC & FP & $\mathrm{FE}$ & GE & GP & GC \\
\hline \multicolumn{7}{|c|}{ (a) Plot positions multiple comparisons are made by row } \\
\hline \multicolumn{7}{|l|}{ Axis 1} \\
\hline Afforestation & e & de & d & c & b & a \\
\hline Stable & $d$ & $d$ & $d$ & c & $b$ & a \\
\hline Deforestation & d & d & d & c & b & a \\
\hline \multicolumn{7}{|l|}{ Axis 2} \\
\hline Afforestation & $a b$ & a & a & $a b$ & $a b$ & b \\
\hline Stable & $b$ & $b$ & $b$ & $a$ & $a b$ & $b$ \\
\hline Deforestation & c & c & b & a & b & b \\
\hline \multicolumn{7}{|c|}{$\begin{array}{l}\text { (b) Types of interfaces multiple comparisons are made by column } \\
\text { Axis } 1\end{array}$} \\
\hline Afforestation & $\mathrm{a}$ & $\mathrm{a}$ & $a$ & a & n.s. & n.s. \\
\hline Stable & $b$ & $b$ & $b$ & a & n.s. & n.s. \\
\hline Deforestation & $b$ & $b$ & $b$ & $b$ & n.s. & n.s. \\
\hline \multicolumn{7}{|l|}{ Axis 2} \\
\hline Afforestation & a & a & a & a & a & n.s. \\
\hline Stable & b & b & b & $a b$ & $a b$ & n.s. \\
\hline Deforestation & b & $\mathrm{b}$ & b & b & $\mathrm{b}$ & n.s. \\
\hline
\end{tabular}

grassland positions were significantly different regardless of the type of interface (Fig 3, Table 2a). In the case of afforestation, the three recent forest positions were significantly different from those of stable and deforestation interfaces (Table 2b) and closest to those of grasslands (Fig. 3). In cases of deforestation, only the floristic composition of recent grassland edge was significantly different from those of stable and afforestation interfaces and relatively close to those of forests.
On the second CCA axis, the average scores for recent forest (afforestation) were significantly higher than those of ancient forest (either in the stable or deforestation contexts) regardless of the plot position (Fig. 3, Table 2b). In contrast, the average scores for recent grassland (deforestation) were significantly lower than those of ancient grasslands in stable interfaces, except at the grassland core. Moreover, regardless the type of interface, the average scores of the edge positions were highest, and the values decreased to the periphery and core positions in both habitats (Fig. 3, Table 2a).

Analysing forest and grassland plots together, variation partitioning (Fig. 4a) showed a slightly stronger effect of plot position $(5.5 \%)$ than of history $(4.1 \%)$ on vegetation composition but a much larger joint effect of these two factors $(11.3 \%)$. This joint effect was almost entirely the result of the habitat effect (forest vs grassland). In contrast, when analysing by habitat (forest or grassland only), the shared effects were near zero. In forest (Fig. 4b) the variations were more due to history $(7.3 \%)$ than plot position $(4.2 \%)$, and in grassland (Fig. $4 \mathrm{c}$ ) the reverse was observed with $2.5 \%$ and $9 \%$ of the variation explained, respectively.

\section{Discussion}

\section{Structure of plant communities along stable forest- grassland interfaces}

A decreasing pattern of species richness was observed from the edge to the grassland core, which is consistent with the few studies conducted along entire forest-grassland interfaces (Erdős et al. 2011, 2013). However, no trend was found in forests, while a significantly higher species richness at the edge has often been observed in previous studies (Murcia 1995; Chabrerie et al. 2013). Regardless of habitat, this pattern of higher species richness at the two edges seems to only be valid when the species richness of the two habitats is high (e.g. forest-grassland interface; Ries et al. 2004). When the species richness of one of the (a) Forest and grassland

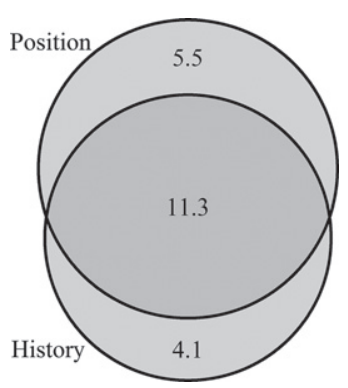

(b) Forest

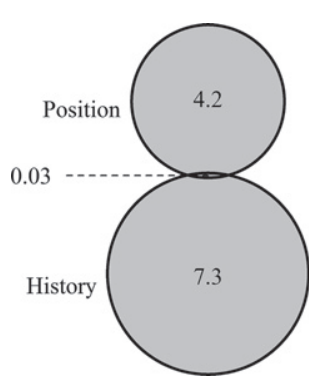

(c) Grassland

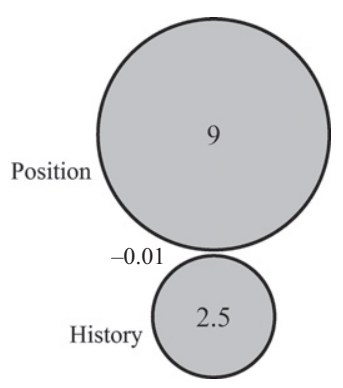

Fig. 4. Variation partitioning of the effects of plot position and land-use history on plant community composition of (a) forest and grassland plots (132 plots, 225 species), (b) only forest plots (66 plots, 166 species) and (c) only grassland plots (66 plots, 210 species). Numbers are percentages of the total variation explained (\%). 
two habitats is low (e.g. forest-arable field interface), specialist species of the richest habitat almost exclusively transgress within edges. As a consequence, species richness is expected to decrease from the core to the edge in the richest habitat but increase from the core to the edge in the least rich habitat (Ries et al. 2004; Alignier et al. 2014). This may explain the ambiguous and/or reverse distribution patterns of species richness that are sometimes observed when edge studies do not include both adjacent habitats (Marchand \& Houle 2006; Dutoit et al. 2007; Gieselman et al. 2013). In our study, both adjacent habitats were sampled, so the nearly constant species richness from the forest core to the forest edge can only be explained by the negative influence of the edge effect on the forest specialist richness and the almost total absence of transgressive grassland specialist species.

We showed an asymmetric transgression of species between habitats in stable interfaces: many forest specialist species were able to transgress the forest-grassland boundary into the grassland edge and periphery, while few grassland specialist species were able to transgress into forest. The lower number of transgressive grassland specialist species is consistent with several studies showing that most species of open habitats seem unable to penetrate the forest-grassland boundary (Brothers \& Spingarn 1992; Honnay et al. 2002). As most species of open habitats are heliophilous, an explanation is that a dense ligneous stratum at the forest edge can affect the intensity of the edge effect by reducing the amount of incident light that reaches the understorey vegetation (Murcia 1995; Honnay et al. 2002). In contrast, the larger number of transgressive forest specialist species may be explained by their ability to colonize open habitats during natural successions and by the large range of light intensities encountered under forest canopies. The 'spill-over' mechanism favours the dispersion of forest and grassland specialist species into adjacent habitats, but 'edges as enhanced habitats' only permits the establishment and persistence of forest specialist species at the grassland edge and periphery. In addition, the higher species richness of grassland edges relative to forest edges was mainly due to the larger number of generalist species (see also Liira \& Paal 2013), probably because grassland edges are more heterogeneous and less ecologically constrained than other positions.

Our study found marginal existence of edge specialist species in stable forest-grassland interfaces. Only 12 species out of $244(4.9 \%)$ were significantly associated with edges when $r_{\mathrm{pb}}$ coefficient calculations used single habitats, and only eight species when calculations used habitats and their combinations. In agreement with these results, the few quantitative studies on edge species have reported a small number of edge specialist species (Lloyd et al. 2000; Erdős et al. 2011).

\section{Colonization credits and extinction debts induced by edge displacements}

Several forest species, particularly zoochorous or anemochorous species, have rather good dispersion abilities (Bossuyt et al. 1999; Bellemare et al. 2002), but other forest species, particularly ancient forest and core specialist species, are particularly poor dispersers (Matlack 1994; Verheyen et al. 2003). Our observation of a lower forest specialist richness in recent forest and in the adjacent grassland edge following afforestation confirms the existence of a colonization credit due to the absence of the poorly dispersing species (Bellemare et al. 2002). In contrast, forest specialist richness was higher in recent grassland following deforestation. This extinction debt may reflect the long persistence capabilities of forest specialist species, which have mostly perennial underground organs such as bulbs or rhizomes (Hermy et al. 1999). Like most grassland species, such functional traits allow these forest species to withstand disturbance from agricultural practices (Lavorel et al. 1997). They are also probably able to tolerate high levels of light for a period of time.

Grassland specialist species were found to be almost absent in ancient forest, even at the forest edge, and they showed an extinction debt in recent forest. To a lesser extent, the edge specialist species also exhibited higher richness in recent forest, reflecting an extinction debt. There are two possible explanations for these extinction debts: (i) either grassland and edge specialist species have long persistence capabilities and their populations are declining slowly over time (Hylander \& Ehrlén 2013), or (ii) variations in micro-environmental conditions in time and space, particularly in recent forest, allow the intermittent establishment and persistence of grassland and edge specialists over long periods (Albrecht et al. 2016). Two other indirect explanations may also be considered: (iii) the complete closure of the forest canopy is a long process, which guarantees decades of environmental conditions that are relatively close to those required by grassland and edge specialist species, notably in terms of light availability (Chabrerie et al. 2013), and (iv) edge displacements by afforestation are probably more recent than those linked to deforestation in our study region. According to these explanations, recent forests could be more or less longterm shelters for some grassland and edge specialist species. It must be noted that, without consideration of land-use changes, specialist species in extinction debt in recent habitats may have falsely appear to be generalists. Finally, generalist species were more numerous in recent forest, and to 
a lesser extent, in recent grassland compared to ancient habitats. In these recent habitats, the ratio of habitat specialist species to generalist species decreases at least in the short and medium term (see also Liira \& Paal 2013), but this ratio could increase again following the recovery of the environmental conditions in the new habitats and the payment of the colonization credit after a 'relaxation time' (Diamond 1972).

Because of the preferential extension of recent forests at the periphery of the ancient forests, the extinction debt and the colonization credit can be confused with edge effects over long distances (Bergès et al. 2013; Pellissier et al. 2013). Our results validate the edge displacements as an important explanatory factor of the variability in the distance of influence of edge effects found in the literature (Harper et al. 2005).

Relative influences of the edge effect and edge displacement on the distribution of plant species

Within stable interfaces, plant communities showed their strongest differences in species richness and floristic composition between forest edges and grassland edges, which confirms that the ancient edges form a low-permeability barrier to specialist species between adjacent habitats (Chabrerie et al. 2013; Cousins 2013), with the notable exception of transgressive forest specialist species. Although smaller differences in species richness and floristic composition were observed between forest edges and grassland edges in the afforestation and deforestation interfaces, our results do not allow us to determine whether a higher permeability of recent edges interferes with the process of extinction debts and colonization credits. Nevertheless, these results reflect the strong differences in the ecology of species between forest and grassland, the latter being more heliophilous and hygrophilous, but rather less nitrophilous, basophilic and thermophilic. Despite controlling for topography during the selection of study sites, the plant communities of grasslands appeared more hygrophilous than those of forests, which may reflect either improved moisture retention in grassland soils or preferential creation of grasslands by farmers on the wetter soils. Furthermore, we found higher proportions of heliophilous, hygrophilous and nitrophilous species in recent forest compared to ancient forest. In contrast, recent grasslands had proportionally fewer heliophilous, hygrophilous and nitrophilous species than ancient grasslands, but only at the edge and periphery. Consequently, autecology of species confirms the interactive effects of extinction debt and colonization credit with the 'spill-over' and the 'edges as enhanced habitats' mechanisms at the recent grassland edge and periphery. At grassland cores, floristic compositions were very similar regardless of the type of interface, which may reflect the homogenizing effect of more intensive management practices at the core compared to the periphery and edge (Gaujour et al. 2012).

Finally, the influence of edge displacement was shown to be larger than that of the edge effect in forests, while the opposite was found in grasslands. Our results confirm a slower ecological succession in recent forests resulting from afforestation compared to recent grasslands resulting from deforestation, which promoted extinction debt and colonization credit on the one hand and partly masked the edge effect on the other. In contrast, deforestation and mowing practices appear responsible for the rapid succession in recent grassland, at least at the grassland core, thus limiting the effect of land-use change in favour of the edge effect. Our results demonstrate a space-time link between forest and grassland resulting from the combined effects of distance-to-edge and land-use change on the species composition of plant communities in forest-grassland interfaces. Thanks to the study of the afforestation of grasslands and of the deforestation, we could highlight the role of extinction debt in addition to that of colonization credit. Because edge movements have been common during the last centuries in our changing agricultural landscapes, patterns of species distribution according to distance-to-edge can only be understood when considering former land-use history.

\section{Acknowledgements}

We are grateful to Olivier Nourrigeon who provided the vectorized map of present land use in the PNRL and to Patrick Behr, Pierre Montpied and three trainees for their help in floristic surveys. We thank Laurent Bergès for his thoughtful comments on data analysis. We thank the two reviewers for their helpful comments. This study was partly funded by the 'Ecosystèmes Forestiers, Agroressources, Biomolécules et Alimentation' (EFABA) federative institute of sector A2F of Lorraine University through the project 'PRECOFOR'. The UMR 1137 EEF is supported by the French National Research Agency through the Laboratory of Excellence ARBRE (ANR-12LABXARBRE-01).

\section{References}

Albrecht, M.A., Becknell, R.E. \& Long, Q. 2016. Habitat change in insular grasslands: woody encroachment alters the population dynamics of a rare ecotonal plant. Biological Conservation 196: 93-102.

Alignier, A., Alard, D., Chevalier, R. \& Corcket, E. 2014. Can contrast between forest and adjacent open habitat explain the edge effects on plant diversity? Acta Botanica Gallica 161: 253-259. 
Bellemare, J., Motzkin, G. \& Foster, D.R. 2002. Legacies of the agricultural past in the forested present: an assessment of historical land-use effects on rich mesic forests. Journal of Biogeography 29: 1401-1420.

Bergamini, A., Peintinger, M., Fakheran, S., Moradi, H., Schmid, B. \& Joshi, J. 2009. Loss of habitat specialists despite conservation management in fen remnants 1995-2006. Perspectives in Plant Ecology, Evolution and Systematics 1 1: 65-79.

Bergès, L., Pellissier, V., Avon, C., Verheyen, K. \& Dupouey, J.-L. 2013. Unexpected long-range edge-to-forest interior environmental gradients. Landscape Ecology 28: 439-453.

Bergès, L., Avon, C., Arnaudet, L., Archaux, F., Chauchard, S. \& Dupouey, J.-L. 2015. Past landscape explains forest periphery-to-core gradient of understorey plant communities in a reforestation context. Diversity and Distributions 22: 3-16.

Borcard, D., Legendre, P. \& Drapeau, P. 1992. Partialling out the spatial component of ecological variation. Ecology 73: 10451055.

Bossuyt, B., Hermy, M. \& Deckers, J. 1999. Migration of herbaceous plant species across ancient-recent forest ecotones in central Belgium. Journal of Ecology 87: 629-638.

Brothers, T.S. \& Spingarn, A. 1992. Forest fragmentation and alien plant invasion of central Indiana old-growth forests. Conservation Biology 6: 91-100.

Chabrerie, O., Jamoneau, A., Gallet-Moron, E. \& Decocq, G. 2013. Maturation of forest edges is constrained by neighbouring agricultural land management. Journal of Vegetation Science 24: 58-69.

Cousins, S.A.O. 2013. Moving towards the edge: matrix matters!. Journal of Vegetation Science 24: 7-8.

De Cáceres, M.D. \& Legendre, P. 2009. Associations between species and groups of sites: indices and statistical inference. Ecology 90: 3566-3574.

De Cáceres, M., Legendre, P. \& Moretti, M. 2010. Improving indicator species analysis by combining groups of sites. Oikos 119: 1674-1684.

Diamond, J.M. 1972. Biogeographic kinetics: estimation of relaxation times for avifaunas of Southwest Pacific islands. Proceedings of the National Academy of Sciences of the United States of America 69: 3199-3203.

Dutoit, T., Buisson, E., Gerbaud, E., Roche, P. \& Tatoni, T. 2007. The status of transitions between cultivated fields and their boundaries: ecotones, ecoclines or edge effects? Acta Oecologica 31: 127-136.

Ellenberg, H., Weber, H.E., Düll, R., Wirth, V., Werner, W. \& Paulißen, D. 1992. Zeigerwerte von Pflanzen in Mitteleuropa. Scripta Geobotanica 18: 1-258.

Erdős, L., Gallé, R., Bátori, Z., Papp, M. \& Körmöczi, L. 2011. Properties of shrub-forest edges: a case study from South Hungary. Open Life Sciences 6: 639-658.

Erdős, L., Gallé, R., Körmöczi, L. \& Bátori, Z. 2013. Species composition and diversity of natural forest edges: edge responses and local edge species. Community Ecology 14: 48-58.

Gaujour, E., Amiaud, B., Mignolet, C. \& Plantureux, S. 2012. Factors and processes affecting plant biodiversity in permanent grasslands. A review. Agronomy for Sustainable Development 32: 133-160.

Gieselman, T.M., Hodges, K.E. \& Vellend, M. 2013. Humaninduced edges alter grassland community composition. Biological Conservation 158: 384-392.

Harper, K.A., Macdonald, S.E., Burton, P.J., Chen, J., Brosofske, K.D., Saunders, S.C., Euskirchen, E.S., Roberts, D., Jaiteh, M.S. \& Esseen, P.-A. 2005. Edge influence on forest structure and composition in fragmented landscapes. Conservation Biology 19: 768-782.

Herlin, I.S. 2001. Approaches to forest edges as dynamic structures and functional concepts. Landscape Research 26: 27-43.

Hermy, M., Honnay, O., Firbank, L., Grashof-Bokdam, C. $\delta$ Lawesson, J.E. 1999. An ecological comparison between ancient and other forest plant species of Europe, and the implications for forest conservation. Biological Conservation 91: 9-22.

Honnay, O., Verheyen, K. \& Hermy, M. 2002. Permeability of ancient forest edges for weedy plant species invasion. Forest Ecology and Management 161: 109-122.

Hurlbert, S.H. 1978. The measurement of niche overlap and some relatives. Ecology 59: 67-77.

Hylander, K. \& Ehrlén, J. 2013. The mechanisms causing extinction debts. Trends in Ecology e Evolution 28: 341-346.

Jackson, S.T. \& Sax, D.F. 2010. Balancing biodiversity in a changing environment: extinction debt, immigration credit and species turnover. Trends in Ecology o Evolution 25: 153160.

Lavorel, S., McIntyre, S., Landsberg, J. \& Forbes, T.D.A. 1997. Plant functional classifications: from general groups to specific groups based on response to disturbance. Trends in Ecology OEvolution 12: 474-478.

Liira, J. \& Paal, T. 2013. Do forest-dwelling plant species disperse along landscape corridors? Plant Ecology 214: 455-470.

Lloyd, K.M., McQueen, A.A.M., Lee, B.J., Wilson, R.C.B., Walker, S. \& Wilson, J.B. 2000. Evidence on ecotone concepts from switch, environmental and anthropogenic ecotones. Journal of Vegetation Science 1 1: 903-910.

Marchand, P. \& Houle, G. 2006. Spatial patterns of plant species richness along a forest edge: what are their determinants? Forest Ecology and Management 223: 113-124.

Matlack, G.R. 1994. Plant species migration in a mixed-history forest landscape in eastern North America. Ecology 75: 14911502.

Murcia, C. 1995. Edge effects in fragmented forests: implications for conservation. Trends in Ecology $\theta$ Evolution 10: 58-62.

Pellissier, V., Bergès, L., Nedeltcheva, T., Schmitt, M.-C., Avon, C., Cluzeau, C. \& Dupouey, J.-L. 2013. Understorey plant species show long-range spatial patterns in forest patches according to distance-to-edge. Journal of Vegetation Science 24: 9-24.

Ries, L. \& Sisk, T.D. 2004. A predictive model of edge effects. Ecology 85: 2917-2926.

Ries, L. \& Sisk, T.D. 2010. What is an edge species? The implications of sensitivity to habitat edges. Oikos 119: 1636-1642. 
Ries, L., Fletcher, R.J., Battin, J. \& Sisk, T.D. 2004. Ecological responses to habitat edges: mechanisms, models, and variability explained. Annual Review of Ecology, Evolution, and Systematics 35: 491-522.

Strayer, D.L., Power, M.E., Fagan, W.F., Pickett, S.T.A. \& Belnap, J. 2003. A classification of ecological boundaries. BioScience 53: 723-729.

Van der Maarel, E. 1979. Transformation of cover-abundance values in phytosociology and its effects on community similarity. Vegetatio 39: 97-114.

Vellend, M., Verheyen, K., Flinn, K.M., Jacquemyn, H., Kolb, A., Van Calster, H., Peterken, G., Graae, B.J., Bellemare, J., (...) \& Hermy, M. 2007. Homogenization of forest plant communities and weakening of species-environment relationships via agricultural land use. Journal of Ecology 95: 565-573.

Verheyen, K., Guntenspergen, G.R., Biesbrouck, B. \& Hermy, M. 2003. An integrated analysis of the effects of past land use on forest herb colonization at the landscape scale. Journal of Ecology 91: 731-742.

\section{Supporting Information}

Additional Supporting Information may be found in the online version of this article:

Appendix S1. Sampling scheme.

Appendix S2. Variables characterizing the plots.

Appendix S3. Distinction between generalist and infrequent species for the single habitat classification.

Appendix S4. Species pools of forest specialists, edge specialists, grassland specialists and generalist species. Point-biserial correlation coefficients calculated for single groups of plots in stable interfaces.

Appendix S5. Species pools of forest specialists, forest + edge specialists, edge specialists, edge + grassland specialists, grassland specialists and generalist species. Point-biserial correlation coefficients calculated for single groups of plots and their combinations in stable interfaces. 